\title{
NEW THINKING OF MULTI-OBJECTIVE PROGRAMMING WITH CHANGEABLE SPACE - IN SEARCH OF EXCELLENCE
}

\author{
Jih-Jeng HUANG ${ }^{a}$, Gwo-Hshiung TZENG ${ }^{\mathrm{b}, \mathrm{c}}$ \\ a Department of Computer Science \& Information Management, Soochow University, Taipei, Taiwan \\ ${ }^{\mathrm{b}}$ Institute of Management of Technology, National Chiao Tung University, Hsinchu, Taiwan \\ ${ }^{\circ}$ Graduate Institute of Urban Planning, National Taipei University, San Shia, Taiwan
}

Received 02 August 2012; accepted 30 June 2013

\begin{abstract}
Multi-objective programming (MOP) is a branch of mathematical programming that has been widely used to deal with various practical problems. With the introduction of new technologies and business models, a paradigm shift in optimization problems is gradually taking place from fixed to flexible optimization. For example, many organizations use outsourcing or business process reengineering (BPR) to improve or upgrade their objective and technological coefficients to achieve better performance. Hence, traditional MOP models should be extended from the concept of fixed to changeable parameters, called changeable space, which includes decision space and objective space. In this paper, we propose three kinds of MOP model with changeable parameters to help decision-makers achieve the desired point (aspiration level), which is better than the ideal point.
\end{abstract}

Keywords: decision making, mathematical model, multi-objective, optimization, multi-objective programming (MOP), optimization problems, changeable parameters (changeable space), desired point (aspiration level).

Reference to this paper should be made as follows: Huang, J.-J.; Tzeng, G.-H. 2014. New thinking of multi-objective programming with changeable space - in search of excellence, Technological and Economic Development of Economy 20(2): 254-273.

JEL Classification: C44, C61, D20, M11.

\section{Introduction}

It has been over 60 years since the simplex algorithm was proposed by Dantzig (1947) as a discipline for handling optimization problems. In the same year, von Neumann (1947) developed the theory of duality as a linear optimization solution and applied it in the field of

Corresponding author Jih-Jeng Huang

E-mail: jjhuang@scu.edu.tw 
game theory. The original motivation of mathematical programming was the need to solve complex planning problems in wartime operations. After World War II, this technique was extended to solve various industrial optimization problems with great success. However, traditional mathematical programming models, whether single-objective programming (SOP) or multi-objective programming (MOP), consider optimizing a fixed objective function(s) under given constraints or resources. Therefore, it can only be viewed as an optimal tool within a system rather than as a tool to optimize the system itself. More specifically, most progress in traditional optimization methods has focused on algorithms or convergence properties to derive the optimal solution within a system, not on evolving the optimality concept itself, nor on expanding the notions of true optimization (Zeleny 1998).

The postulate of traditional mathematical programming not only simplifies problems themselves, but also reflects the situation which companies faced in the past. As time has gone by, new practical problems have become more complicated than in the past. An increasing number of practical phenomena supports the necessity for changeable parameters of mathematical programming. For example, the emergence of dispatched workers or leased workers provides the flexibility of a company to adjust its human-resource allocation. In addition, a system can dynamically tune up its production resource allocation through satellite manufacturers or outsourcing. Hence, modern systems and problems should be considered to re-design and re-shape according to their flexibility, not their fixation (Zeleny 1998).

Another obvious case to justify the necessity for changeable parameters in mathematical programming is virtual organizations. Virtual organizations can be regarded as a network of independent firms that join together to capture specific market opportunities (Davidow, Malone 1992; Lambrechts et al. 2009). Each firm in a virtual organization contributes core competences and shares resources. Hence, the resources and production capabilities of a firm in a virtual organization are changeable and variable. Hence, mathematical programming models should also be flexible enough to deal with these problems. That is, we should relax the parameters of mathematical programming models from fixation to changeability.

De Novo programming was proposed by Zeleny $(1982,1986)$ to first extend traditional mathematical programming to relax the assumption of fixed resource allocations. The main concept of "De Novo programming" is to reconstruct the original constraints by incorporating the information of resources' unit prices. Hence, the result of De Novo programming can determine the optimal resource allocation of a system and its objectives so that trade-offs among objectives can be appropriately eliminated (Zeleny 1990; Huang et al. 2005, 2006; Chen, Tzeng 2009).

Although Shi (1999) proposed the concept of a possible debt to De Novo programming, there are some significant differences between the two models. Shi's model (Shi 1999) enables the available resources to be flexible. Then, a possible debt can borrow additional money from a bank with a fixed interest rate to achieve the preferences of multiple decision makers and the corresponding objectives. On the other hand, the proposed models try to achieve the desired levels which are set by a decision maker under the objective of the minimum total debt. In addition, the proposed models consider the situations of the changeable parameters of the objective and technological coefficients. 
In addition, the concept of the "changeable space" of mathematical programming was also proposed by (Yu, ChiangLin 2006; ChiangLin et al. 2007; Yu, Chen 2010, 2012) to illustrate that the parameters of a system may in practice be changed via investment, outsourcing or production improvement. However, they did not develop a complete model to resolve the mathematical programming problems of changeable parameters, also called "changeable space". The basic concept of changeable decision space and aspiration level can be shown as in Fig. 1.

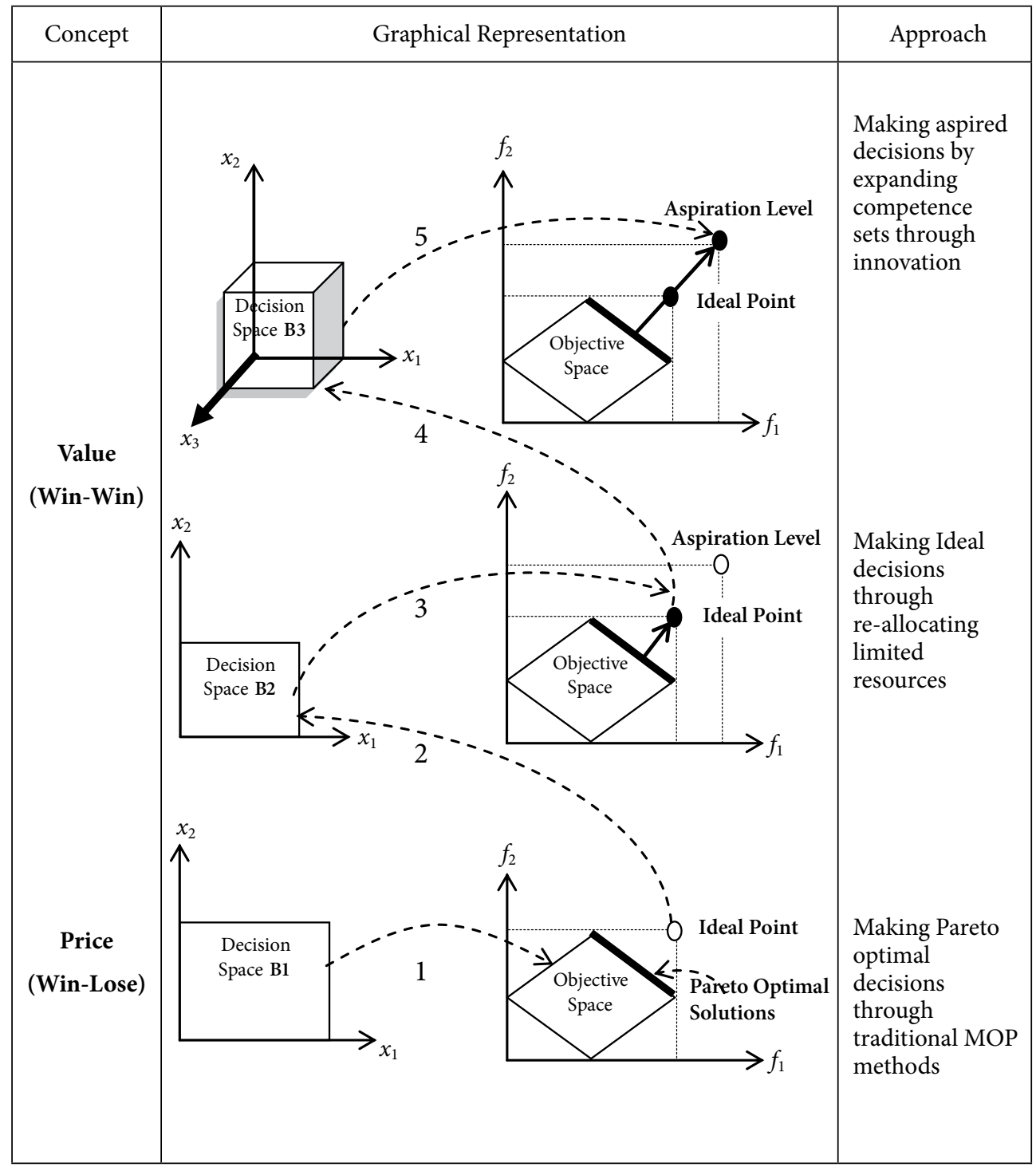

Fig. 1. Basic concept of changeable decision space and aspiration level (Liou, Tzeng 2012) 


\section{De Novo programming}

De Novo programming can be considered as an optimal method for solving resource allocation problems. Traditionally, a multiple objective resource allocation problem (Hackman, Platzman 1990) could be formulated to maximize the following multi-objective knapsack problem:

$$
\begin{array}{cc}
\max & \boldsymbol{z}=\boldsymbol{C} \boldsymbol{x} ; \\
\text { s.t. } & \boldsymbol{A} \boldsymbol{x} \leq \boldsymbol{b}, \\
& \boldsymbol{x} \geq \mathbf{0},
\end{array}
$$

where: $\boldsymbol{C}$ is the objective coefficient matrix; $\boldsymbol{x}$ denotes the variable vector; $\boldsymbol{A}$ denotes the technological coefficient matrix and the $\boldsymbol{b}$ vector denotes the maximum limited resource portfolios.

However, traditional resource allocation models may be inappropriate in the real world. First, since the components of $\boldsymbol{b}$ are determined in advance, the optimal solution heavily depends on whether resources are appropriately allocated. In addition, although it is rational to allocate resources using the above model in a hierarchical system, when resources can be brought from markets, the factor of a resource's unit price should be considered, and so the traditional methods are no longer suitable. In order to deal with this issue, De Novo programming was proposed.

De Novo programming was proposed by Zeleny $(1982,1986)$ to re-design or re-shape a given system to achieve an ideal point based on given resources (subject to constraints). $\mathrm{He}$ suggested that trade-offs are properties of an inadequately designed system and thus can be eliminated through designing a better, preferably optimal system.

The usefulness of De Novo programming is that it can consider the following MOP problem (Zeleny 1982). Assume a manufacturer produces two different products, suits and dresses, in quantities $x$ and $y$. Each of them requires five different resources, nylon through golden thread, according to technologically determined requirements. Unit prices of resources are also given, as shown in Table 1.

Table 1. Resource allocation of Zeleny's example

\begin{tabular}{ccccc}
\hline \multirow{2}{*}{ Unit price } & \multirow{2}{*}{ Resource } & \multicolumn{2}{c}{ Technological coefficients } & \multirow{2}{*}{ No. of units } \\
& & $x_{1}=1$ & $x_{2}=1$ & 20 \\
\hline 30 & Nylon & 4 & 0 & 24 \\
\hline 40 & Velvet & 2 & 6 & 60 \\
\hline 9.5 & Silver thread & 12 & 4 & 10.5 \\
\hline 20 & Silk & 0 & 3 & 26 \\
\hline 10 & Golden thread & 4 & 4 & \\
\hline
\end{tabular}

If two objectives, namely profit $\left(f_{1}\right)$ and quality index $\left(f_{2}\right)$, are considered by the company, we can formulate the following two-objective mathematical programming problem as:

$$
\begin{aligned}
\max & f_{1}=400 x_{1}+300 x_{2} ; \\
\max & f_{2}=6 x_{1}+8 x_{2} ; \\
\text { s.t. } & 4 x_{1} \leq 20, \\
& 2 x_{1}+6 x_{2} \leq 24, \\
& 12 x_{1}+4 x_{2} \leq 60,
\end{aligned}
$$




$$
\begin{aligned}
& 3 x_{2} \leq 10.5, \\
& 4 x_{1}+4 x_{2} \leq 26, \\
& x_{1}, x_{2} \geq 0,
\end{aligned}
$$

where $f_{1}$ and $f_{2}$ denote the objectives: profit and quality index, respectively. Let the two objectives be equally important. Then, if we employ the compromise solutions and set $p=2$, we can obtain the optimal solution: $x_{1}=3.9837, x_{2}=2.5163, f_{1}=2348.37$ and $f_{2}=44.03$. However, the above solution may be unsatisfactory to the decision makers, due to the inappropriate resource portfolio.

Therefore, Zeleny (1998) proposed the concept of an optimal portfolio of resources, which is the design of system resources with a sense of integration, so that there are no trade-offs in a newly designed system. The original idea of De Novo programming was that productive resources should not be engaged individually and separately because resources are not independent. Later, various issues, such as considering fuzzy coefficients (Li, Lee 1990a, b, 1993; Lee 1994), other optimum-path ratios (Shi 1995) and the 0-1 programming problem (Kim et al. 1993), have been proposed to deal with more complicated situations. Based on the above concept, via breaking the constraints of fixed resources, De Novo programming can eliminate trade-offs between objectives to achieve the aspiration solution.

The procedures of De Novo programming can be described as follows (Zeleny 1982):

1. Find the aspiration level vector $\left(z^{u}\right)$ by solving each objective function of a system separately as

$$
\begin{array}{ll}
\max & z_{k}^{u}=\boldsymbol{c}_{k} \boldsymbol{x}, k=1, \ldots, m ; \\
\text { s.t. } & V \boldsymbol{x} \leq B, \\
& \boldsymbol{x} \geq \mathbf{0},
\end{array}
$$

where: $\boldsymbol{z}^{u}=\left[\begin{array}{llll}z_{1}^{u} & z_{2}^{u} & \cdots & z_{m}^{u}\end{array}\right]$ denotes the aspiration level vector; $\boldsymbol{V}=\boldsymbol{p} \boldsymbol{A}$ denotes the unit cost vector; $\boldsymbol{p}$ is the resource's unit price vector and $B$ denotes the total budget.

2. Identify the minimum budget $B^{*}$ and its corresponding resource allocation $\left(x^{*}\right.$ and $\left.\boldsymbol{b}^{*}=\boldsymbol{A} \boldsymbol{x}^{*}\right)$ with the aspiration level, such as:

$$
\begin{array}{ll}
\min & B^{*}=V \boldsymbol{x}^{*} ; \\
\text { s.t. } & \boldsymbol{C} \boldsymbol{x}=\boldsymbol{z}^{*}, \\
& \boldsymbol{x} \geq \mathbf{0} .
\end{array}
$$

3. Use the optimum-path ratio ( $r$ ) to obtain the final solution $(\boldsymbol{z}, \boldsymbol{x}$ and $\boldsymbol{b})$.

$$
\begin{aligned}
& \boldsymbol{z}=r \times \boldsymbol{z}^{*} ; \\
& \boldsymbol{x}=r \times \boldsymbol{x}^{*}
\end{aligned}
$$

and

$$
\boldsymbol{b}=r \times \boldsymbol{b}^{*},
$$

where $r=B / B^{*}$. 
If we reconsider the previous example and deal with that problem using De Novo programming, we can obtain the optimal resource allocation as: $x=4.03$ and $y=2.54, b_{1}=16.12$, $b_{2}=23.3, b_{3}=58.52, b_{4}=7.62$ and $b_{5}=26.28$ under the total budget $B=2600$ to generate $f_{1}=2375$ and $f_{2}=44.5$ (ideal point). Comparing this result with the previous example, we can find that two objective values deriving from De Novo programming are better than that of traditional MOP, due to the appropriate resource allocation.

The procedures of De Novo programming proposed by Zeleny (1982) only derive one possible Pareto solution. Formally, we can formulate De Novo programming as:

$$
\begin{array}{ll}
\max & \boldsymbol{C} \boldsymbol{x} ; \\
\text { s.t. } & \boldsymbol{p}^{\prime} \boldsymbol{A} \boldsymbol{x} \leq B, \\
& \boldsymbol{A} \boldsymbol{x} \leq \boldsymbol{b}, \\
& \boldsymbol{x} \geq \mathbf{0} .
\end{array}
$$

Next, we can solve the above problem using traditional MOP models, such as goal programming or compromise solutions, to derive the optimal solution of De Novo programming.

Another kind of extension for MOP is to consider changeable parameters of MOP models. De Novo programming, like traditional mathematical programming, also postulates that the parameters of models, such as technological coefficients and objective coefficients, are fixed. However, these parameters may be changeable if we consider exogenous factors, such as increasing investment, improving efficiency and time advancement (Chiang Lin et al. 2007).

ChiangLin et al. (2007) proposed a single-objective programming model with changeable parameters as:

$$
\begin{array}{ll}
\max & \sum_{j=1}^{m}\left(c_{j 1}+c_{j 2} y\right) x_{j} ; \\
\text { s.t. } & \sum_{j=1}^{m} a_{k j} x_{j} \leq\left(d_{k 1}+d_{k 2} z\right), \quad k=1, \ldots, r, \\
& 0 \leq y \leq y^{\prime}, 0 \leq z \leq z^{\prime}, x_{j} \geq 0, \quad j=1,2, \ldots, m,
\end{array}
$$

where: $c_{j 1}$ denotes the original $j^{\text {th }}$ objective coefficient; $c_{j 2}$ is the $j^{\text {th }}$ new objective coefficient caused by $y$, which could be investment in advertisement, service and distribution channels, etc.; $d_{k 1}$ denotes the original $k^{\text {th }}$ available resources and $d_{k 2}$ is the $k^{\text {th }}$ new extra resource caused by $z$, which could be making alliances, outsourcing, etc. Usually, $y$ and $z$ have upper limit constraints, namely $y^{\prime}$ and $z^{\prime}$, respectively, or Eq. (9) will become an unbounded problem.

Let us modify the previous example (as shown in Table 2) to demonstrate Yu's model. Assume the firm can increase its objective coefficients and resources through investment $(y)$ and purchase $(z)$. The profits of products $x_{1}$ and $x_{2}$ can be increased by 3 and 4 units separately and the quality index of products $x_{1}$ and $x_{2}$ can be increased 0.3 and 0.4 separately through the investment. In addition, the number of units of each resource can be increased through the unit purchase. Finally, the investment and purchase levels should be less than 7 units, separately, and the total of the investment and purchase is limited to 10 . 
Table 2. Modified example to demonstrate Yu's model

\begin{tabular}{lcccc}
\hline \multicolumn{1}{c}{ Resource } & \multicolumn{2}{c}{ Technological coefficients } & No. of units & $\begin{array}{c}\text { Unit Purchase } \\
\text { Benefit }\end{array}$ \\
\hline Nylon & $x_{1}=1$ & $x_{2}=1$ & 20 & 0.3 \\
\hline Velvet & 4 & 0 & 24 & 0.3 \\
\hline Silver thread & 2 & 6 & 60 & 0.3 \\
\hline Silk & 12 & 4 & 10.5 & 0.3 \\
\hline Golden thread & 0 & 3 & 26 & 0.3 \\
\hline
\end{tabular}

Although Yu's model only considers the single-objective situation, we can simply transform it to a multi-objective situation by using the compromise solutions. Here, we use the compromise solution and set $p=2$ to calculate the problem as follows:

$$
\begin{aligned}
\max & f_{1}=400 x_{1}+300 x_{2}+y\left(3 x_{1}+4 x_{2}\right) \\
\max & f_{2}=6 x_{1}+8 x_{2}+y\left(0.3 x_{1}+0.2 x_{2}\right) \\
\text { s.t. } & 4 x_{1} \leq 20+0.3 z \\
& 2 x_{1}+6 x_{2} \leq 24+0.3 z \\
& 12 x_{1}+4 x_{2} \leq 60+0.3 z \\
& 3 x_{2} \leq 10.5+0.3 z \\
& 4 x_{1}+4 x_{2} \leq 26+0.3 z \\
& 0 \leq y, z \leq 7 \\
& y+z \leq 10 \\
& x_{1}, x_{2}, y, z \geq 0 .
\end{aligned}
$$

The optimal solution can be calculated as: $y=7, z=3, x_{1}=4.1655, x_{2}=2.5595, f_{1}=2593.19$ and $f_{2}=57.80$. From the above result, besides resource reallocation, we know that the firm can also increase its profit and quality index through outside investment or resource purchase.

Although the previous models extended traditional mathematical programming to deal with more practical problems, they cannot satisfy the purpose of this paper. Let us depict Figure 2 to highlight the purpose of this paper as follows.

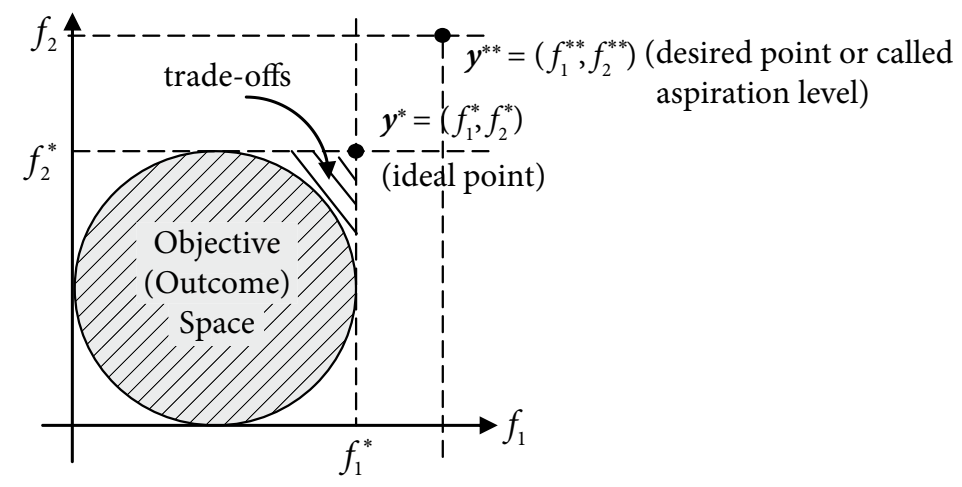

Fig. 2. Basic concept of the desired point 
The original idea of De Novo programming is to re-allocate production resources so that a system's trade-offs can be eliminated, and the ideal point can be achieved. However, the question arises, what if the ideal point still cannot satisfy the decision makers? Although ChiangLin et al. (2007) proposed another model to resolve the above problem, their model still cannot ensure that the desired level, which is wanted by the decision maker, can be achieved. This might be true if adding the effects of $y$ and $z$ still cannot achieve the desired point. In addition, what if a company cannot consider the effects of $y$ or $z$ ? Maybe the above questions should be transformed into the problem that if the desired point is wanted by the decision maker, how can the system be adjusted or re-designed to achieve that point? Decision makers may prefer to know what to do to achieve the desired point (aspiration level) via a re-designed system than what to do to optimize a fixed system.

It is obvious that if the parameters of a system remain constant, the best solution is the ideal point if there is no trade-off among objective functions. However, the desired point (aspiration level), which is better than the ideal point, can never be achieved. Hence, if we want to achieve the desired point (aspiration level), we have to "upgrade" the parameters of the system. Usually, a company may improve its objective/technological coefficients by importing new equipment and methods or by enlarging its fixed resources or promoting its human resources by innovating technology or increasing the total budget, or both, or other ideas. Next, we develop possible models to re-design or re-shape a system to achieve the desired point (aspiration level) according to the concept of changeable space, including decision space and objective (outcome) space.

\section{MOP with changeable parameters}

In practice, there are three basic ways for a system to achieve its desired point (aspiration level): 1) increasing budgets; 2) improving objective coefficients; and 3) upgrading production efficiency. Next, we discuss each situation and develop the corresponding optimal model as follows. In the first situation, a company can make some financing decisions, e.g. to borrow money from the bank or to issue company bonds/stocks to the capital market in order to enlarge/enrich available budgets so as to increase R\&D in innovation and creativity for the value-created knowledge economy. Then, the problem of achieving the desired point (aspiration level) is equivalent to minimizing the extra budget under the given objectives space and decision space (constraints).

Assume a company has $n$ objectives to be achieved and $m$ products are produced. We can incorporate the concepts of financing decisions into MOP and formulate the following model:

$<$ Model 1: MOP with changeable budgets>

$$
\begin{array}{ll}
\min & \widehat{B} ; \\
\text { s.t. } & \sum_{j=1}^{m} c_{i j} x_{i j}=f_{i}^{* *}(\boldsymbol{x}), \quad i=1, \ldots, n, \\
& \boldsymbol{p}^{\prime} \boldsymbol{A} \boldsymbol{x} \leq B+\widehat{B}, \\
& <\text { extra conditions for } \widehat{B}> \\
& \boldsymbol{x} \geq \mathbf{0},
\end{array}
$$


where: $c_{i j}$ denotes the $j^{\text {th }}$ coefficient of the $i^{\text {th }}$ objective function; $f_{i}^{* *}(\boldsymbol{x})$ denotes the desired value of the $i^{\text {th }}$ objective; $\boldsymbol{p}$ denotes the unit price vector of resources; $B$ is the original budget and $\widehat{B}$ denotes the extra budget obtained from financing decisions.

Example 1. Let us reconsider the initial example of producing suits and dresses. If the objective functions and constraints are constant, we can obtain the optimal solution from De Novo programming as $f_{1}=2375$ and $f_{2}=44.5$. However, the decision maker feels unsatisfied with the results and hopes to increase $f_{1}$ (profit) from 2,375 to 2,600 and $f_{2}$ (quality) from 44.5 to 60 , respectively. Hence, one way to achieve the desired solution is to borrow money from the capital markets via financing decisions. Table 3 presents the information related to Example 1.

Table 3. Information table for Example 1

\begin{tabular}{ccccc}
\hline \multirow{2}{*}{ Unit price } & \multirow{2}{*}{ Resource } & \multicolumn{2}{c}{ Technological coefficients } & \multirow{2}{*}{ No. of units } \\
\hline 30 & Nylon & 4 & 0 & $x_{1}=1$ \\
\hline 40 & Velvet & 2 & 6 & $b_{2}$ \\
\hline 9.5 & Silver thread & 12 & 4 & $b_{3}$ \\
\hline 20 & Silk & 0 & 3 & $b_{4}$ \\
\hline 10 & Golden thread & 4 & 4 & $b_{5}$ \\
\hline
\end{tabular}

The problem of Example 1 is to derive the minimum extra budget which can achieve the desired point and determine the corresponding resource allocation. Next, we can formulate the following linear programming to solve the problem of Example 1 as:

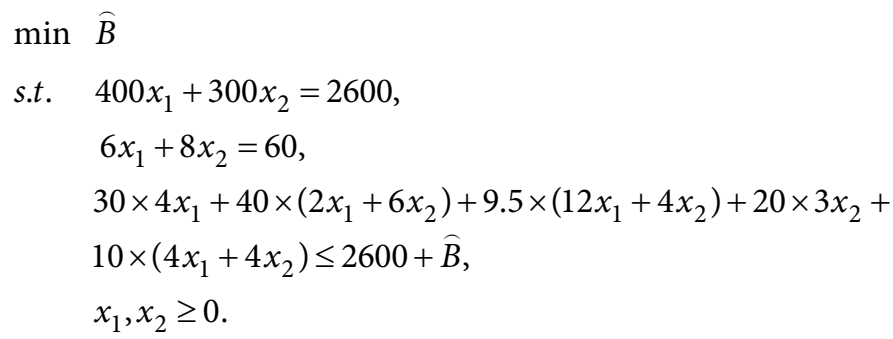

By solving the above problem, we obtained that the extra budget needed is $\widehat{B}=376$, producing $x_{1}=2$ and $x_{2}=6$. The corresponding resource allocation can be calculated as $b_{1}=8$, $b_{2}=40, b_{3}=48, b_{4}=18$ and $b_{5}=32$. The corresponding profit and quality index are exactly equal to 2,600 and 60 , respectively.

Comparing the result with De Novo programming and the proposed models, it can be seen that the proposed method can find a way to achieve the desired point which cannot be achieved by using De Novo programming. It is clear that the only way to go beyond the ideal point is to ask for outside help. Therefore, if the system hopes to achieve the desired point, it needs an extra $\$ 376$. However, if the extra budget needed is equal to zero, it means that the original system is good enough to achieve the desired point, and the proposed model reduces to De Novo programming. 
Besides borrowing money from capital markets, a company can also achieve its desired goal through improving the objective coefficients of a system, e.g. economics of scale, electronic commerce, total quality management (TQM) and eliminating middle agencies. In this situation, a company should consider the unit improving cost of each objective coefficient and determine the optimal budget allocation between the improving costs and production resources. Then, we can develop a MOP model with changeable objective coefficients as follows:

$<$ Model 2: MOP with changeable objective coefficients $>$

$$
\begin{array}{ll}
\min & \widehat{B} ; \\
\text { s.t. } & \sum_{j=1}^{m}\left(c_{i j}+\widehat{c}_{i j}\right) x_{i j}=f_{i}^{* *}(\boldsymbol{x}), \quad i=1, \ldots, n, \\
& \boldsymbol{p}^{\prime} \boldsymbol{A} \boldsymbol{x}+\sum_{i=1}^{n} \sum_{j=1}^{m} p_{i j}^{c} \widehat{c}_{i j} \leq B+\widehat{B}, \\
& <\text { extra conditions for } p_{i j}^{c} \text { and } \widehat{c}_{i j}> \\
& \boldsymbol{x} \geq \mathbf{0},
\end{array}
$$

where $p_{i j}^{c}$ denotes the unit upgrading cost with respect to the $j^{\text {th }}$ product coefficient of the $i^{\text {th }}$ objective function and $\widehat{c}_{i j}$ is the $j^{\text {th }}$ upgrading product coefficient of the $i^{\text {th }}$ objective function.

Example 2. Following the previous example of producing suits and dresses, if the company cannot borrow money from capital markets, but also hopes to increase $f_{1}$ (profit) from 2,375 to 2,600 and $f_{2}$ (quality) from 44.5 to 60 , another way is to improve its objective coefficients through possible strategies or technologies. Therefore, we assume that the unit improving costs of the objective coefficients are $\$ 0.200, \$ 0.289, \$ 2.225$ and $\$ 2.487$, respectively, as shown in Table 4.

Table 4. Information table for Example 2

\begin{tabular}{ccccccc}
\hline \multicolumn{2}{c}{ Objective coefficients } & \multirow{2}{*}{\begin{tabular}{c}
\multirow{2}{*}{ Unit price } \\
$x=1$
\end{tabular}} & Resource & Technological coefficients & \multirow{2}{*}{ No. of units } \\
\hline $400(\$ 0.200)$ & $300(\$ 0.289)$ & 30 & Nylon & 4 & 0 & $b_{1}$ \\
\hline $6(\$ 2.225)$ & $8(\$ 2.487)$ & 40 & Velvet & 2 & 6 & $b_{2}$ \\
\hline & 9.5 & Silver thread & 12 & 4 & $b_{3}$ \\
\hline & 20 & Silk & 0 & 3 & $b_{4}$ \\
\hline & 10 & Golden thread & 4 & 4 & $b_{5}$ \\
\hline
\end{tabular}

Next, we can formulate the following mathematical programming to consider achieving the desired points via improving the objective coefficients as follows:

$$
\begin{array}{ll}
\min & \widehat{B} \\
\text { s.t. } & \left(400+\widehat{c}_{11}\right) x_{1}+\left(300+\widehat{c}_{12}\right) x_{2}=2600, \\
& \left(6+\widehat{c}_{21}\right) x_{1}+\left(8+\widehat{c}_{22}\right) x_{2}=60, \\
& 30 \times 4 x_{1}+40 \times\left(2 x_{1}+6 x_{2}\right)+9.5 \times\left(12 x_{1}+4 x_{2}\right)+20 \times 3 x_{2}+ \\
& 10 \times\left(4 x_{1}+4 x_{2}\right)+\left(0.200 \widehat{c}_{11}+0.289 \widehat{c}_{12}+2.225 \widehat{c}_{21}+2.487 \widehat{c}_{22}\right) \leq 2600+\widehat{B}, \\
& x_{1}, x_{2} \geq 0 .
\end{array}
$$


Solving the above problem, we can obtain the extra budget $\widehat{B}=0$. The result means that no extra budget is needed for achieving the desired point. Then, we can also derive $x_{1}=4.43$, $x_{2}=2.70, \widehat{c}_{11}=3.51, \widehat{c}_{12}=0.18, \widehat{c}_{21}=1.44$, and $\widehat{c}_{22}=2.00$. In addition, the corresponding resource allocation can be assigned as $b_{1}=17.72, b_{2}=25.06, b_{3}=17.72, b_{4}=8.10, b_{5}=28.52$, profit $=2600$ and the quality index $=60$. We should highlight that if $\widehat{B} \neq 0$, it means that we still cannot achieve the desired point via improving objective coefficients. Therefore, it indicates that extra budget is also needed for the system to achieve the desired point. Otherwise, we should consider another possibility.

The last situation discussed here is that a company may expand its outcome space through upgrading the technology coefficients of a system. For example, a company can adopt business process reengineering (BPR), new information technologies or enterprise resource management (ERP) to increase its production efficiency, i.e. upgrading its technology coefficients. Hence, we can conceptualize the above description to formulate the following model:

$<$ Model 3: MOP with Changeable technological coefficients >

$$
\begin{array}{ll}
\min & \widehat{B} ; \\
\text { s.t. } & \sum_{j=1}^{m} c_{i j} x_{i j}=f_{i}^{* *}(\boldsymbol{x}), \quad i=1, \ldots, n, \\
& \boldsymbol{p}^{\prime}(\boldsymbol{A}-\widehat{\boldsymbol{A}}) \boldsymbol{x}+\sum_{k=1}^{r} \sum_{j=1}^{m} p_{k j}^{a} \widehat{a}_{k j} \leq B+\widehat{B} \\
& <\text { extra conditions for } p_{i j}^{a} \text { and } \widehat{a}_{i j}> \\
& \boldsymbol{x} \geq \mathbf{0},
\end{array}
$$

where $\widehat{\boldsymbol{A}}=[\widehat{a}]_{k j}$ is the upgrading technological coefficient matrix and $p_{k j}^{a}$ is the unit upgrading cost with respect to the $j^{\text {th }}$ technology coefficient of the $k^{\text {th }}$ constraint.

Example 3. We can follow the previous example of producing suits and dresses to address the following problem. If the company still cannot achieve the desired point through adding extra budget or improving objective coefficients, the last possible way is to update the technological coefficients of the system. Therefore, we assume each unit updating cost of the technological coefficients can be defined and presented as shown in Table 5.

Table 5. Information table for Example 3

\begin{tabular}{ccccccc}
\hline \multicolumn{2}{c}{ Objective coefficient } & \multirow{2}{*}{\begin{tabular}{c}
\multirow{2}{*}{ Unit price } \\
R 1
\end{tabular}} & Resource & \multicolumn{2}{c}{ Technological coefficients } & \multirow{2}{*}{ No. of units } \\
\hline 400 & 300 & 30 & Nylon & $4(\$ 0.5)$ & 0 & $b_{1}$ \\
\hline 6 & 8 & 40 & Velvet & $2(\$ 0.5)$ & $6(\$ 0.27)$ & $b_{2}$ \\
\hline & 9.5 & Silver thread & $12(\$ 0.27)$ & $4(\$ 0.26)$ & $b_{3}$ \\
\hline & 20 & Silk & 0 & $3(\$ 0.25)$ & $b_{4}$ \\
\hline & 10 & Golden thread & $4(\$ 0.25)$ & $4(\$ 0.25)$ & $b_{5}$ \\
\hline
\end{tabular}


Incorporating the information of the unit updating cost of the technological coefficients, we can formulate the following mathematical programming model:

$$
\begin{array}{ll}
\min & \widehat{B} \\
\text { s.t. } & 400 x_{1}+300 x_{2}=2600, \\
& 6 x_{1}+8 x_{2}=60, \\
& 30 \times\left(4-\widehat{a}_{11}\right) x_{1}+40 \times\left(\left(2-\widehat{a}_{21}\right) x_{1}+\left(6-\widehat{a}_{22}\right) x_{2}\right)+9.5 \times\left(\left(12-\widehat{a}_{31}\right) x_{1}+\right. \\
& \left.\left(4-\widehat{a}_{32}\right) x_{2}\right)+20 \times\left(3-\widehat{a}_{42}\right) x_{2}+10 \times\left(\left(4-\widehat{a}_{51}\right) x_{1}+\left(4-\widehat{a}_{52}\right) x_{2}\right)+ \\
& 0.5 \widehat{a}_{11}+0.5 \widehat{a}_{21}+0.27 \widehat{a}_{22}+12 \widehat{a}_{31}+4 \widehat{a}_{32}+3 \widehat{a}_{42}+4 \widehat{a}_{51}+4 \widehat{a}_{52} \leq 2600+\widehat{B}, \\
& x_{1}, x_{2} \geq 0 .
\end{array}
$$

Solving the above problem, we can obtain the extra budget $\widehat{B}=0$. The result means that no extra budget is needed for achieving the desired point. Then, we can also derive $x_{1}=2.42$, $x_{2}=5.69, \hat{a}_{11}=2.03, \hat{a}_{21}=1.27, \hat{a}_{22}=0.30, \hat{a}_{31}=0.27, \hat{a}_{32}=0.25, \hat{a}_{42}=0.26, \hat{a}_{51}=0.25$ and $\widehat{a}_{52}=0.26$. In addition, the corresponding resource allocation can be assigned as $b_{1}=4.76$, $b_{2}=34.20, b_{3}=49.72, b_{4}=15.59, b_{5}=30.36$, profit $=2600$ and quality index $=60$.

In the previous models, we can use one of the three ways to try to achieve the desired point. In practice, three situations could exist simultaneously. Therefore, a more general model of changeable parameters can be considered to incorporate the previous three situations as:

$$
\begin{array}{ll}
\min & \widehat{B} ; \\
\text { s.t. } & \sum_{j=1}^{m}\left(c_{i j}+\widehat{c}_{i j}\right) x_{j} \geq f_{i}^{* *}(x), \quad i=1, \ldots, n, \\
& \boldsymbol{p}^{\prime}(\boldsymbol{A}-\widehat{\boldsymbol{A}}) \boldsymbol{x}+\sum_{i=1}^{n} \sum_{j=1}^{m} p_{i j}^{c} \widehat{c}_{i j}+\sum_{i=1}^{n} \sum_{j=1}^{m} p_{i j}^{a} \widehat{a}_{i j} \leq B+\widehat{B}, \\
& <\text { extra conditions for } \widehat{B}, p_{i j}^{c}, \widehat{c}_{i j}, p_{i j}^{a} \text { and } \widehat{a}_{i j}> \\
& \boldsymbol{x} \geq \mathbf{0} .
\end{array}
$$

If $\widehat{B}=0$, it means that the desired point can be achieved without increasing the budget. The decision maker can improve objective coefficients (when $\widehat{c}_{i j} \neq 0$ ), update the technological coefficients (when $\widehat{a}_{i j} \neq 0$ ) or both (when $\widehat{c}_{i j} \neq 0$ and $\widehat{a}_{i j} \neq 0$ ) to achieve the desired point. On the other hand, if $\widehat{B} \neq 0$, it means that the original system cannot be achieved through updating the objective or the technological coefficients. Hence, the only way is to increase the budget through borrowing money from capital markets.

Note that the proposed models enable the objective and technological coefficients to be changeable. Although this characteristic makes the model more flexible, it may suffer from problems of computation and solubility. Hence, we propose the concept of convex programming, and the corresponding proof to justify that our models is rational and solvable as follows.

Definition 1. A mathematical programming is called convex programming if and only if its objective and constraint functions are convex. Note that it is clear that least-squares and linear programming are special kinds of convex programming. 
Definition 2. Suppose a function $f: R^{n} \rightarrow R$ is twice differentiable. Then $f$ is convex if and only if its domain, $D(f)$, is a convex set and its Hessian matrix is positive semidefinite.

As we know, convex programming is a special kind of non-linear programming. Like linear programming, it generally has no analytic solution. However, for a convex optimization problem, all locally optimal solutions are globally optimal. Hence, there are many algorithms, such as interior-point method, which can be used for solving these problems reliably and efficiently. In addition, the time complexity of the convex programming is approximately $\max \left\{n^{3}, n^{2} m, F\right\}$, where $n$ is the number of variables, $m$ is the number of constraints, and $F$ is the cost of the evaluating objectives, constraints and their first and second derivatives. In a general situation, the complexity of a convex programming model belongs to the polynomial problems. It can be easily solved by today's computers.

The proposed models belong to convex programming.

Proof:

Equations (10)-(12) are special cases of Equation (13). Hence, if Equation (13) is a convex programming problem, Models 1-3 are convex programming problems.

First, we want to examine the Hessian matrices of the objective and constraints of Equation (13). For convenience of the operations, we assume

$$
\begin{gathered}
f(\widehat{B})=\widehat{B}, \\
g\left(x_{j}, \widehat{c}_{i j}\right)=f_{i}^{* *}(\boldsymbol{x})-\sum_{j=1}^{m}\left(c_{i j}+\widehat{c}_{i j}\right) x_{j} \leq 0, \\
h\left(x_{j}, \widehat{c}_{i j}, \widehat{a}_{i j}, B\right)=\boldsymbol{p}^{\prime}(\boldsymbol{A}-\widehat{\boldsymbol{A}}) \boldsymbol{x}+\sum_{i=1}^{n} \sum_{j=1}^{m} p_{i j}^{c} \widehat{c}_{i j}+\sum_{i=1}^{n} \sum_{j=1}^{m} p_{i j}^{a} \widehat{a}_{i j}-B+\widehat{B} \leq 0 .
\end{gathered}
$$

Then, the Hessian matrix of each equation is calculated, separately, as:

$$
\begin{gathered}
\nabla^{2} f(\widehat{B})=[0], \\
\nabla^{2} g_{i}\left(x_{j}, \widehat{c}_{i j}\right)=[0]_{2 m \times 2 m}, \forall i=1, \ldots, n, \\
\nabla^{2} h\left(x_{j}, \widehat{c}_{i j}, \widehat{a}_{i j}, B\right)=[0] .
\end{gathered}
$$

Clearly, all of the matrices above are positive semidefinite. Hence, the problem of Equation (13) is a convex programming problem. Similarly, we can prove that Models 1-3 are examples of convex programming. This proof also justifies the rationale and solubility of the proposed models.

Next, we propose the related findings according to the results of the illustrated examples.

\section{Discussion}

Traditional MOP is used to solve optimal problems with a given and fixed system. However, an increasing number of flexible systems/organizations, such as team-based and virtual organizations, are being proposed to replace traditional ones. Therefore, the problem of system optimization should be extended from inside to outside the system. That is, we should design a new system rather than optimizing a given system through changing the system parameters. In practice, these methods include BPR, outsourcing, dispatching workers, etc. 
In this paper, we develop three MOP models for decision-makers to design or plan a system. The first model retains the original parameters of objective and technological coefficients but only considers borrowing money from capital markets. The second model enables objective functions to be changeable so that a system can improve its objective coefficients to achieve the desired point. The last model considers that the technological coefficients of a system are changeable. Therefore, the desired point can be achieved through updating its technological coefficients.

Next, we can illustrate how to expand the changeable spaces for achieving the desired point (aspiration level), as shown in Fig. 3. Note that in Fig. 2, the left and right quadrant charts denote the decision and objective spaces, respectively. The curves pointed from the decision space to objective space indicate the corresponding corner solutions of the programming problem. In addition, Fig. 4 displays the sets of different objective spaces. It can be seen that the objective set is gradually enlarged if we release the parameters of the traditional mathematical programming problems. That is, the optimal solution can be upgraded by considering changeable parameters of mathematical programming.
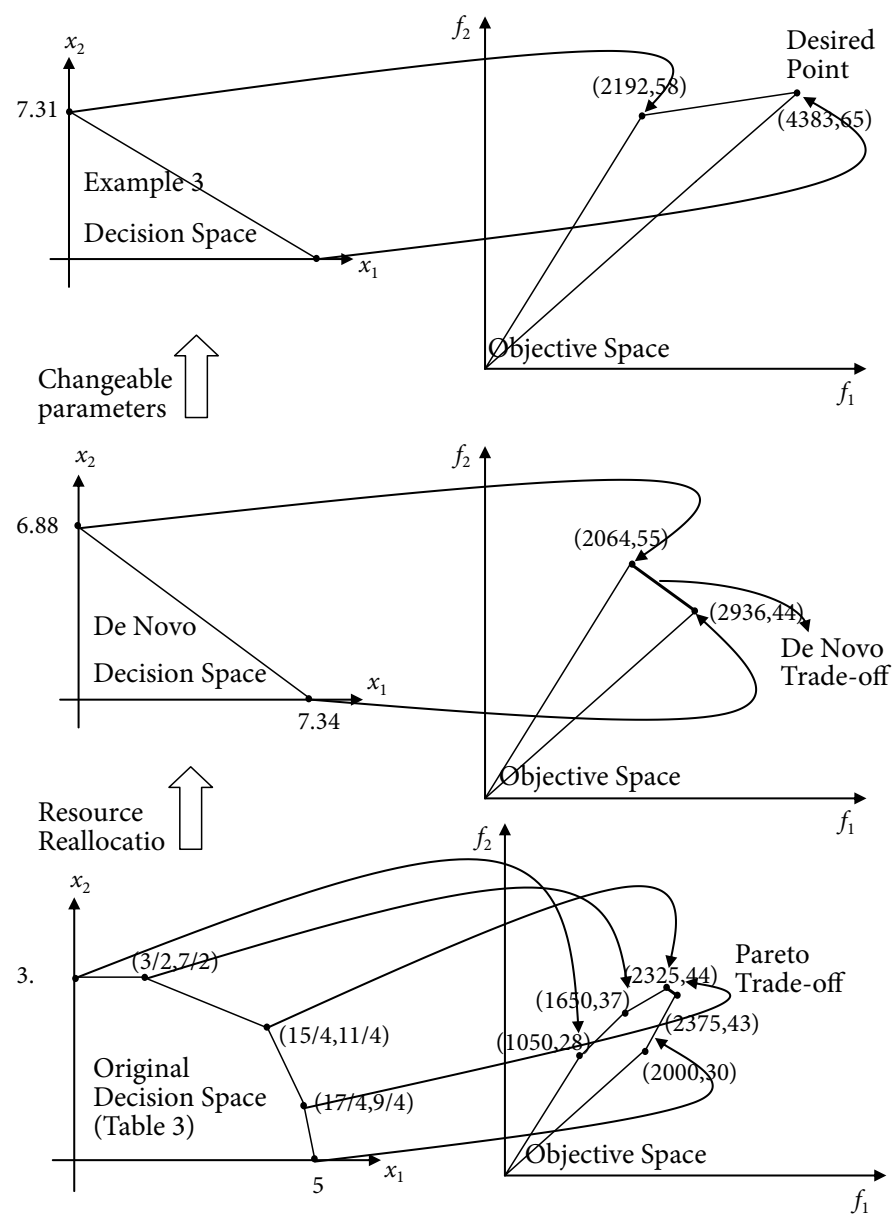

Fig. 3. Changeable spaces for achieving the desired point 


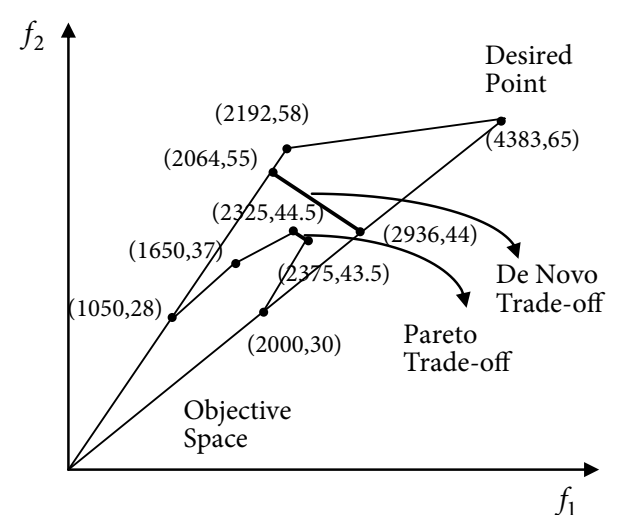

Fig. 4. A comparison of objective space

It can be seen that the decision spaces of the illustrated example are expanded gradually through resource re-allocation or changeable parameters. Therefore, the corresponding objective spaces are changeable and create the possibility of achieving better solutions. As we know, the original decision space will cause the Pareto solution, due to the trade-off between objectives. Although the De Novo programming enables the possibility of resource re-allocation to obtain a better result, it still causes a De Novo trade-off because of the fixation of the system parameters. Therefore, the only way to achieve the desired point is to expand the decision space via changeable parameters. Then, we can obtain the desired point without trade-off between objectives.

Here, we compare the three models, De Novo, Yu's model and the proposed model, as follows. Although the three models share the same purpose of system design, there are several significant differences between them. First, De Novo incorporates the variables, resource unit prices and total budget, to re-allocate the available resources. On the other hand, Yu's model enables the objective coefficients and resources to be changeable via outside investment or time. However, the proposed model considers all possible situations of parameter changeability. In addition, the purpose of the proposed model is to find a way with the minimum budget to achieve the desired objectives set with minimum budget. In contrast, De Novo and Yu's model derives the optimal solution under re-given objectives and/or constraints. The comparisons of these models are presented in Table 6.

In addition, the relationship between these models can be represented as shown in Fig. 5 .

Recently, the concept of habitual domains (HD) has been proposed and supports the flexible or changeable parameters of decision spaces. Habitual domains (Yu 1980, 1984, 1985, 1990, 1991) refer to the set of human's thinking, judging, responding, experience, and knowledge. Therefore, it is clear that HDs play a key role in affecting human behaviour. To improve the quality of decision-making, people should think about two major problems: 1) how to polish the existing HDs; 2) how to expand the existing HDs. Recently, many papers have been proposed to efficiently expand HDs, known as competence set analysis (Yu, Zhang 1989, 1990, 1992; Li, Yu 1994), and practical applications (Huang et al. 2012; Larbani, Yu 2009a, b, 2012a, b). These methods can be used to significantly improve the quality of decision-making. 
Table 6. The differences between the system design of the models

\begin{tabular}{lccc}
\hline $\begin{array}{l}\text { Changeable } \\
\text { parameters }\end{array}$ & Budget & Resource and Objective & $\begin{array}{c}\text { Tudget, Resource, } \\
\text { Objective and Technology }\end{array}$ \\
\hline Optimality via & Resource Reallocation & $\begin{array}{c}\text { Outside investment } \\
\text { or time }\end{array}$ & Both \\
\hline Optimal solution & Model determined & Model determined & $\begin{array}{c}\text { Determined by } \\
\text { decision-makers }\end{array}$ \\
\hline Purpose & $\begin{array}{l}\text { Optimality under } \\
\text { given constraints }\end{array}$ & $\begin{array}{c}\text { Optimality under } \\
\text { given constraints }\end{array}$ & $\begin{array}{c}\text { Optimality by any } \\
\text { possibility }\end{array}$ \\
\hline Objectives & Original objectives & Original objectives & Minimum debt \\
\hline Philosophy & What & What & How \\
\hline
\end{tabular}

\begin{tabular}{|c|c|}
\hline $\begin{array}{l}\text { The } \\
\text { - Technological coefficien } \\
\text { - Achieving the desired le }\end{array}$ & $\begin{array}{l}\text { Model } \\
\text { ble } \\
\text { minimum (extra) budget }\end{array}$ \\
\hline $\begin{array}{l}\text { De Novo Programming } \\
\text { - Resource reallocation } \\
\text { - Resource unit price } \\
\text { - Via budget }\end{array}$ & $\begin{array}{l}\text { Changeable Model } \\
\text { - Objective changeable } \\
\text { - Resource changeable } \\
\text { - Via investment or time }\end{array}$ \\
\hline
\end{tabular}

Fig. 5. The relationship between the models

There are four elements within a habitual domain:

1. The potential domain $(P D)$ - the collection of ideas and actions that can potentially be activated;

2. The actual domain $(A D)$ - the set of ideas and actions that are actually activated;

3. The activation probabilities $(A P)$ - the probabilities that ideas and actions in $P D$ also belong to $A D$;

4. The reachable domain $(R D)$ - the set of ideas and actions that can be attained from a given set in an HD.

Since decision processes depend on the evolution of HDs, an expanding HD can result in effective decisions and preferred solutions. Hence, the expanding HD can be considered as the changeable parameters of the system.

Next, we compare the differences between goal programming and the proposed method as follows. Goal programming was proposed by Charnes and Cooper (1961) to deal with linear MOP problems. The idea of goal programming is to seek a solution which is nearest to the ideal point. Thus, a decision maker should first assign the targets or goal to each objective and then minimize the "distance" from the targets to the objectives (usually we can use $L_{p}$-norm to define the distance between the targets and the objectives) to find the solution. 
The differences between goal programming and the proposed methods can be described as follows. First, the purpose of goal programming is to find a solution, which is located in Pareto solutions, and is closest to the ideal point. However, the purpose of the proposed models is to find out a way that can achieve the desired point via possible changes. Hence, the optimal solution of goal programming is usually worse than the ideal point because of tradeoffs among objective functions. On the other hand, the proposed models can ensure that the desired point, which is better than the ideal point, can be achieved. In sum, goal programming optimizes the objective functions within a given system, i.e. inside optimization. However, the proposed models minimize extra budget with a flexible system, i.e. outside optimization.

Secondly, goal programming optimizes the objective functions of a system with fixed parameters. That is, goal programming solves the problem of what to do to obtain the optimal solution of a system. On the other hand, the proposed models tolerate the parameters of a system being changeable so that the desired point can be achieved through possible adjustments. Hence, goal programming is more suitable for dealing with "what to do" problems, while the proposed models try to answer "how to do" problems.

Finally, the essence of goal programming is to determine an optimal solution in an MOP problem. Therefore, like other traditional MOP methods, such as compromise solutions, it is an optimization method. However, the essence of the proposed models seeks to change or modify the original system so that the desired point can be achieved. Hence, the proposed method can be regarded as an optimal system-design method rather than an optimization method.

On the other hand, we can also highlight the differences between De Novo programming and the proposed models. De Novo programming incorporates the information of resources' unit prices into traditional mathematical programming to design a better system. On the other hand, the proposed method not only considers resources' unit prices but also relaxes other parameters, such as objective and technological coefficients, to be changeable. In addition, the optimal solution of De Novo programming is the ideal point. However, the proposed method seeks ways to achieve the desired point.

Finally, we can highlight the philosophical difference between the proposed method and other MOP methods, including De Novo programming, from the perspective of formal analysis (Tzeng, Huang 2011). All traditional MOP models can be considered as normative models which focus on the problems that decision makers should ideally resolve. However, the proposed method should be regarded as a prescriptive model which considers the methods that decision makers ought to use to improve their decisions.

\section{Conclusions}

Traditional MOP problems focus on the optimization within a system. However, more and more technologies and strategy developments enable systems to be re-designed or re-shaped to perform better. Hence, we should extend traditional MOP from a normative model to a prescriptive model. In this paper, we propose three kinds of MOP with changeable parameters, i.e. budget, objective coefficients and technological coefficients, to help decision-makers to achieve their desired points. 


\section{References}

Charnes, A.; Cooper, W. W. 1961. Management models and industrial applications of linear programming. NY: Wiley \& Sons. 859 p.

Chen, K. C.; Tzeng, G. H. 2009. Perspective strategic alliances and resource allocation in supply chain systems through the De Novo programming approach, International Journal of Sustainable Strategic Management 1(3): 320-339. http://dx.doi.org/10.1504/IJSSM.2009.026285

ChiangLin, C. Y.; Lai, T. C.; Yu, P. L. 2007. Linear programming models with changeable parameters theoretical analysis on "taking loss at the ordering time and making profit at the delivery time", International Journal of Information Technology \& Decision Making 6(4): 577-589. http://dx.doi.org/10.1142/S0219622007002745

Dantzig, G. B. 1947. Maximization of a linear function of variables subject to linear inequalities, in Koopman, T. C. (Ed.). Activity analysis of production and allocation. New York: John Wiley and Sons.

Davidow, W. H.; Malone, M. S. 1992. The virtual corporation: structuring and revitalizing the corporation for the 21st century. NY: Harper Collins Publishers. 294 p.

Hackman, S. T.; Platzman, L. K. 1990. Near optimal solution of generalized resource allocation problems with large capacities, Operations Research 38(5): 902-910. http://dx.doi.org/10.1287/opre.38.5.902

Huang, H. S.; Larbani, M.; Yu, P. L. 2012. Quantification and applications of identification spheres, Journal of Optimization Theory and Applications 31(1): 97-109.

Huang, J. J.; Tzeng, G. H.; Ong, C. S. 2005. Motivation and resource allocation for strategic alliance through De Novo perspective, Mathematical and Computer Modeling 41(6-7): 711-721. http://dx.doi.org/10.1016/j.mcm.2004.05.007

Huang, J. J.; Tzeng, G. H.; Ong, C. S. 2006. Choosing best alliance partners and allocating optimal alliance resources using the fuzzy multi-objective dummy programming model, Journal of Operational Research Society 57(10): 1216-1223. http://dx.doi.org/10.1057/palgrave.jors.2602108

Kim, H.; Ida, K.; Gen, M. 1993. A De Novo approach for bicriteria 0-1 linear programming with interval coefficients under gub structure, Computers and Industrial Engineering 25(1): 17-20. http://dx.doi.org/10.1016/0360-8352(93)90210-O

Lambrechts, F.; Grieten, S.; Bouwen, R.; Corthouts, F. 2009. Process consultancy revisited. Taking a 'relational practice' prespective, Journal of Applied Behavioral Science 45(1): 39-58. http://dx.doi.org/10.1177/0021886308326563

Larbani, M.; Yu, P. L. 2009a. Two-person second-order games, Part 1: formulation and transition anatomy, Journal of Optimization Theory and Applications 141(3): 619-639. http://dx.doi.org/10.1007/s10957-008-9487-y

Larbani, M.; Yu, P. L. 2009b. Two-person second-order games, Part 2: restructuring operations to reach a win-win profile, Journal of Optimization Theory and Applications 141(3): 641-659. http://dx.doi.org/10.1007/s10957-008-9488-x

Larbani, M.; Yu, P. L. 2012a. Decision making and optimization in changeable spaces, a new paradigm, Journal of Optimization Theory and Applications 155(3): 727-761. http://dx.doi.org/10.1007/s10957-012-0103-9

Larbani, M.; Yu, P. L. 2012b. n-person second-order games: a paradigm shift in game theory, Journal of Optimization Theory and Applications 149(3): 447-473. http://dx.doi.org/10.1007/s10957-011-9799-1

Lee, E. S. 1994. On fuzzy De Novo programming, in Delgado, M.; Kacprzyk, J.; Verdegay, J. L.; Vila, M. A. (Eds.). Fuzzy optimization: recent advances. Heidelberg: Physica-Verlag, 33-44.

Li, R. J.; Lee, E. S 1990a. Multicriteria De Novo programming with fuzzy parameters, Computers and Mathematics with Applications 19(1): 13-20. http://dx.doi.org/10.1016/0898-1221(90)90097-4 
Li, R. J.; Lee, E. S. 1990b. Fuzzy approaches to multicriteria De Novo programs, Journal of Mathematical Analysis and Applications 153(1): 97-111. http://dx.doi.org/10.1016/0022-247X(90)90268-K

Li, R. J.; Lee, E. S. 1993. De novo programming with fuzzy coefficients and multiple fuzzy goals, Journal of Mathematical Analysis and Applications 172(1): 212-220. http://dx.doi.org/10.1006/jmaa.1993.1018

Li, H. L.; Yu, P. L. 1994. Optimal competence set expansion using deduction graph, Journal of Optimization Theory and Applications 80(1): 75-91. http://dx.doi.org/10.1007/BF02196594

Liou, J. H.; Tzeng, G. H. 2012. Comments on "Multiple criteria decision making MCDM methods in economics: an overview", Technological and Economic Development of Economy 18(4): 672-695. http://dx.doi.org/10.3846/20294913.2012.753489

Shi, Y. 1995. Studies on optimum-path ratios in De Novo programming problems, Computers and Mathematics with Applications 29(1): 43-50. http://dx.doi.org/10.1016/0898-1221(94)00247-I

Shi, Y. 1999. Optimal system design with multiple decision makers and possible debt: a multicriteria De Novo programming approach, Operations Research 47(5): 723-729. http://dx.doi.org/10.1287/opre.47.5.723

Tzeng, G. H.; Huang, J. J. 2011. Multiple attribute decision making - methods and applications. NW: CRC Press. 349 p.

von Neumann, J. 1947. Discussion of a maximization problem. Institute for Advanced Study, Princeton University.

Yu, P. L. 1980. Behavior bases and habitual domains of human decision/behavior-concepts and applications, in Fandel, G.; Gal, T. (Eds.). Multiple criteria decision-making, theory and applications. New York: Springer-Verlag, 511-539. http://dx.doi.org/10.1007/978-3-642-48782-8_34

Yu, P. L. 1984. Introduction to decision dynamics, second order games and habitual domains, MCDM: past decade and future trends, in Zeleny, M. (Ed.). A source book of multiple criteria decision-making. Connecticut, Greenwich: Jai Press, 26-49.

Yu, P. L. 1985. Habitual domain analysis, a way to reduce human fuzziness, in Proceedings of Annual Japanese Symposium on Fuzzy Systems, 28-29 May, 1985, Kyoto, Japan, 41-54.

Yu, P. L. 1990. Forming winning strategies, an integrated theory of habitual domains. Berlin, Heidelberg, New York, London, Paris, Tokyo: Springer-Verlag. 392 p. http://dx.doi.org/10.1007/978-3-642-61295-4

Yu, P. L. 1991. Habitual domains, Operations Research 39(6): 869-876. http://dx.doi.org/10.1287/opre.39.6.869

Yu, P. L.; Chen, Y. C. 2010. Blinds, fuzziness and habitual domain tools in decision making with changeable spaces, Human Systems Management 29(4): 231-242.

Yu, P. L.; Chen, Y. C. 2012. Dynamic multiple criteria decision making in changeable spaces: from habitual domains to innovation dynamics, Annals of Operations Research 197(1): 2012-2220. http://dx.doi.org/10.1007/s10479-010-0750-x

Yu, P. L.; ChiangLin, C. Y. 2006. Decision traps and competence dynamics in changeable spaces, International Journal of Information Technology and Decision Making 5(1): 5-18. http://dx.doi.org/10.1142/S0219622006001903

Yu, P. L.; Zhang, D. 1989. Competence set analysis for effective decision making, Control - Theory and Advanced Technology 5(4): 523-547.

Yu, P. L.; Zhang, D. 1990. A foundation for competence set analysis, Mathematical Social Sciences 20(3): 251-299. http://dx.doi.org/10.1016/0165-4896(90)90005-R

Yu, P. L.; Zhang, D. 1992. Optimal expansion of competence sets and decision support, Information Systems and Operational Research 30(2): 68-85.

Zeleny, M. 1982. Multiple criteria decision making. NY: McGraw-Hill. 563 p. 
Zeleny, M. 1986. Optimal system design with multiple criteria: De Novo programming approach, Engineering Costs and Production Economics 10(1): 89-94. http://dx.doi.org/10.1016/0167-188X(86)90029-7

Zeleny, M. 1990. Optimizing given systems vs. designing optimal systems: the De Novo programming approach, General Systems 17(4): 295-307. http://dx.doi.org/10.1080/03081079008935113

Zeleny, M. 1998. Multiple criteria decision making: eight concepts of optimality, Human Systems Management 17(2): 97-107.

Jih-Jeng HUANG is an Associate Professor of Computer Science and Information Management at Soochow University, Taiwan, and teaches research method, multivariate analysis, and capital asset and pricing models, among others. He received his $\mathrm{PhD}$ in Information Management from the National Taiwan University. He has published on these interests widely in journals and conference proceedings. His current research interests include multiple criteria decision making, knowledge management, behavioural economics and finance, and data analysis.

Gwo-Hshiung TZENG is a Distinguished Chair Professor of National Taipei University, Taiwan. He received a Bachelor's degree in Business Management from the Tatung Institute of Technology (1967); a Master's degree in Urban Planning from Chung Hsing University (1971); and a PhD in Management Science from Osaka University, Japan (1977). He is Editor-In-Chief of the International Journal of Operations Research and the International Journal of Information Systems for Logistics and Management, among others. His current research interests include statistics, multivariate analysis, networks, routing and scheduling, multiple criteria decision making, fuzzy theory, hierarchical structure analysis for application to technology management, energy, environment, transportation systems, transportation investment, logistics, location, urban planning, tourism, technology management, electronic commerce, and global supply chains. 